Anales de Geografía de la Universidad Complutense ISSN: 0211-9803

http://dx.doi.org/10.5209/AGUC.30468

\title{
El papel de la Geografía en el análisis del contenido semántico de los topónimos. El caso de Alicante
}

\author{
Joan Carles Membrado-Tena ${ }^{1}$ \\ Recibido: 8 de diciembre del 2016 / Enviado a evaluar: 20 de diciembre del 2016 / Aceptado: 14 de diciembre del 2017
}

\begin{abstract}
Resumen. La relación entre Geografía y Toponimia es incuestionable, ya que los topónimos designan lugares de la superficie terrestre, y la Geografía es la ciencia que estudia los fenómenos que suceden sobre dichos lugares. Además, los nombres de lugar son una herramienta de primer orden para la reconstitución de un paisaje geográfico desaparecido. La Geografía, la Historia y la Lingüística son las tres principales disciplinas auxiliares de la ciencia toponímica. Se lleva a cabo un análisis toponímico de un caso paradigmático al respecto: Alacant/Alicante. Por un lado repasamos su larga y convulsa historia antigua, que implicó el abandono del poblado romano y su traslado -junto con su topónimo- al solar actual en época altomedieval. También realizamos un análisis geográfico de los rasgos físicos del entorno del poblado romano. Por último, proponemos una interpretación etimológica del topónimo y formulamos una hipótesis novedosa sobre el posible contenido semántico del mismo.

Palabras clave: toponimia; Alicante/Alacant/Laqant/Lucentum; Tossal de Manises; L'Albufereta.
\end{abstract}

\section{[en] The role of Geography in the analysis of the meaning of place names. The case of Alicante}

\begin{abstract}
The relation between Geography and Toponymy is remarkable, since place names designate places upon the terrestrial surface, and geography is the science that studies phenomena happening upon those places. In addition, place names are an exceptional tool for reconstituting a disappeared geographic landscape. Geography, History and Linguistics are the three main auxiliary disciplines in order to study place names. A place name analysis of a paradigmatic case (Alacant/Alicante) is studied in this paper. First we review the long, convulsive history of ancient Alicante, which involved the abandonment of its Roman site and its moving -together with its place name- into its current location. We also carry out a geographic analysis of the physical features around the Roman site. Finally we carry out an etymological analysis of this place name and formulate a new hypothesis about its possible meaning.
\end{abstract}

Keywords: place names; Alicante/Alacant/Laqant/Lucentum; Tossal de Manises; L'Albufereta.

Departamento de Geografía. Universitat de València

E-mail: joan.membrado@uv.es 
[fr] Le rôle de la géographie dans l'analyse sémantique des toponymes. Le cas d'Alicante

Résumé. La relation entre la Géographie et la Toponymie est remarquable, puisque les noms de lieux désignent des endroits sur la surface terrestre, et la Géographie est la science qui étudie les phénomènes qui se produisent sur ces lieux. De plus, les noms de lieux sont un outil exceptionnel pour reconstituer un paysage géographique disparu. Géographie, Histoire et Linguistique sont les trois principales disciplines auxiliaires pour étudier les noms de lieux. Une analyse toponymique d'un cas paradigmatique (Alacant/Alicante) est étudiée dans cet article. Tout d'abord, nous passons en revue l'histoire ancienne et convulsive d'Alicante, qui a impliqué l'abandon de son site romain et son déplacement -avec son toponyme- dans son emplacement actuel. Nous effectuons également une analyse géographique des caractéristiques physiques autour du site romain. Enfin, nous effectuons une analyse étymologique de ce nom de lieu et formulons une nouvelle hypothèse sur sa possible sémantique.

Mots clés: Toponymie; Alicante/Alacant/Laqant/Lucentum; Tossal de Manises; L'Albufereta.

Cómo citar. Membrado-Tena, J.C. (2018): El papel de la Geografía en el análisis del contenido semántico de los topónimos. El caso de Alicante. Anales de Geografia de la Universidad Complutense, 38(1), 35-60.

Sumario. 1. Introducción. 2. Objetivos. 3. Antecedentes y estado de la cuestión. 3.1. La ciencia toponímica y sus diversos enfoques metodológicos de análisis. 4. Caso de estudio y metodología. 5. Resultados. 5.1. Geografía de LuCENTUM/Alicante. 5.2. Historia de LuCENTUM/Alicante. 5.3. Etimología de Alicante. 6. Discusión. 7. Consideraciones finales. 8. Bibliografía.

\section{Introducción}

Los topónimos poseen, por definición, un contenido semántico ligado al espacio geográfico, ya que designan una parte del espacio físico que nos rodea. Si los topónimos son el objeto de estudio de la Toponimia y el espacio físico que nos rodea lo es de la Geografía, debe existir necesariamente una relación entre ambas disciplinas, y un interés entre los geógrafos por el análisis toponímico (Tort, 2010: 253). Ello no excluye que los topónimos puedan ser estudiados desde otras perspectivas de análisis, sobre todo la Lingüística y la Historia, pero no cabe duda de que la Geografía es un pilar básico -un punto de partida esencial- en cualquier estudio toponímico (Tort, 2003).

Además, el análisis de los nombres de lugar es una herramienta excepcional para la reconstitución de un paisaje geográfico (físico o humano) ya desaparecido (Riesco, 2010: 22). El geógrafo estadounidense Carl Sauer (1956: 289-291), muy avanzado e influyente en el estudio de los paisajes culturales, consideraba que los topónimos eran la cuarta dimensión -la temporal- de la Geografía, por cuanto su análisis contribuye a la reconstrucción de los paisajes históricos.

La Toponimia rescata el pasado mediante las diferentes capas y estratos de nombres acumulados a lo largo de la historia (Lapesa, 1972; Miranda, 1994; Luján, 1996; Cela, 1998; Algeo y Algeo, 2000; Georgiou, 2010). Esto es fruto del hecho que los nombres de lugar son notablemente conservadores: por un lado, su evolución 
morfológica se detiene a menudo por mucho que los nombres comunes de la misma lengua continúen evolucionando; por otro, muchos sobreviven a la extinción local de la lengua en la que fueron creados. Esta capacidad de supervivencia se explica porque los topónimos no funcionan como unidades léxicas normales: poseen un significado referencial que les permite ser útiles para la designación de un enclave específico y para diferenciarlo del resto de enclaves. Gracias a este mecanismo de "fosilización", los nombres de lugar se convierten en una fuente inagotable de información histórica que posibilita la reconstrucción virtual de un paisaje ya desaparecido.

A pesar del enorme interés que el análisis toponímico reviste dentro de la investigación geográfica, su estudio sigue siendo marginal entre los geógrafos. Lingüistas, y en menor medida historiadores, son los académicos que hasta el momento han mostrado más interés en la toponimia.

\section{Objetivos}

El primer objetivo de este artículo es analizar el contenido semántico del doblete toponímico Alacant/Alicante, en tanto que caso paradigmático del papel crucial de la Geografía -y la Historia- como ciencias auxiliares para la Toponimia. Para llevarlo a cabo repasamos la convulsa historia de LUCENTUM (el nombre romano de Alicante), que implicó el desplazamiento físico tanto del asentamiento como del topónimo, y llevamos a cabo un análisis geográfico de los rasgos físicos que caracterizan el área donde surgió el primer Alacant/Alicante. Además, realizamos un análisis etimológico de este topónimo, con el fin de comprobar si existe coherencia entre su contenido semántico y los rasgos geográficos del área de estudio.

El segundo objetivo es poner de relieve como la Geografía y la Historia son instrumentos de gran utilidad para averiguar el contenido semántico de un topónimo, en especial si no es trasparente. La Lingüística es otro instrumento tanto o más útil para ello que los primeros, pero por sí sola puede no ser suficiente, siendo necesario conocer el entorno geográfico e histórico para poder explicar con mayor certeza el contenido semántico y origen lingüístico de un topónimo.

Antes de explicar el caso de estudio y la metodología seguida en este artículo, conviene repasar los antecedentes teóricos y el estado de la cuestión de la ciencia toponímica, para conocer sus principales paradigmas metodológicos.

\section{Antecedentes y estado de la cuestión}

\subsection{La ciencia toponímica y sus diversos enfoques metodológicos de análisis}

La toponimia, rama de la onomástica que estudia los nombres de lugar, es una disciplina de síntesis donde convergen diferentes campos de conocimiento que interactúan de manera complementaria (Llorente, 1969: 21; Kremer, 2010; Tort, 2010: 
254; Membrado-Tena, 2017: 364). El método clásico de análisis toponímico se centra en la recolección de nombres de lugar y en averiguar su semántica, para lo cual es fundamental acudir a sus tres ciencias auxiliares básicas: la Geografía, la Historia y la Lingüística (Poirier, 1965; Tort, 2001).

Los rasgos geográficos del área designada mediante un topónimo delatan, a menudo, su contenido semántico. La Historia puede ayudar a entender un topónimo en un contexto social determinado, y es un apoyo muy valioso cuando dicho topónimo ha cambiado de ubicación (como es el caso de Alicante). La Lingüística, y más concretamente el análisis etimológico, resulta crucial para desvelar el contenido semántico de un topónimo, especialmente cuando dicho significado no es transparente, sino fósil -es decir, que no se corresponde con palabras usadas en la actualidad en el ámbito geográfico y lingüístico estudiado (Moreu-Rey, 1982: 13; Llorente, 1991; Hernández, 1994: 92). El caso de Alacant/Alicante, que veremos en los resultados y discusión, ilustra el papel primordial de estas tres ciencias para el análisis semántico de los topónimos.

Pero la Toponimia no es solo Historia, Geografía y Lingüística: muchos autores recalcan la vertiente sociológica y filosófica de la Toponimia, y afirman que la producción de nombres para designar lugares a lo largo de la historia nos permite comprender mejor las preocupaciones reales y místicas de las personas que los crearon (Dauzat, 1971: 9). Dorion (1984) añade que, además de Historia, Geografía y Lengua, la toponimia está ligada a la Sociolingüística (a través del análisis de grandes conjuntos de topónimos), la Psicolingüística (los topónimos son signos lingüísticos y como tales, de interés para la semiótica) y la Psicología social (los topónimos son expresiones de una percepción de un lugar).

Cada vez son más numerosos los trabajos que estudian la Toponimia desde una perspectiva ideológico-identitaria, ya que, más allá del contenido semántico, el acto de toponimizar va ligado a un proceso socioespacial que es fruto del contexto ideológico e identitario (Rose-Redwood et al., 2010: 456).

La perspectiva ideológico-identitaria de la toponimia deriva de que los nombres de lugar, alojados en contextos culturales más amplios, inducen (o movilizan) un amplio espectro de emociones que las personas interpretan socialmente de diferente manera (Davidson et al., 2005; Kearney y Bradley, 2009). Los topónimos refuerzan la identidad de un lugar como símbolos que lo designan y definen, y que fortalecen los lazos emocionales con el espacio (Jordan, 2012: 125-129). Los topónimos deben ser entendidos como parte de un proceso socioespacial dinámico que está detrás de la identificación de las personas con un pasado que, en forma de historia y memoria, proporciona un vínculo afectivo para la vida y la identidad de las personas en el presente (Fuchs, 2015: 13).

Coromines (1965: 7) ligaba el interés por el estudio de la Toponimia a la curiosidad inherente del ser humano, que es particularmente intensa en el caso de los nombres de lugar, ya que estos poseen una fuerte carga identitaria para las personas con las que entran en contacto cada día. Algunos autores distinguen entre la Etimología, que estudia el origen y la filiación lingüística de un nombre, y la Etiología, que estudia las motivaciones que han originado un topónimo (Moreu-Rey, 
1995: 47). Las motivaciones sociales que permiten la creación de un topónimo dependen del grupo humano que lo acepta o lo rechaza como identificador de un lugar, y esta elección está ligada a la mentalidad social y a los valores imperantes en cada época (Terrado, 2007: 384).

Riesco destaca "la estrecha conexión entre paisaje, memoria histórica e identidad, que se expresa mediante determinados topónimos, impuestos o favorecidos, que privilegian determinadas lecturas del hecho espacial" (2010: 25). Esta conexión entre topónimos e identidad es especialmente evidente en áreas que fueron colonizadas (como América y África) o dominadas por políticas totalitarias (como las de la Europa de entreguerras). Las potencias coloniales o los regímenes autoritarios crearon o transformaron determinada toponimia como un mecanismo para consolidar el nuevo orden político dominante. Con la retirada de la metrópoli o la derrota del régimen, los nuevos gobernantes reemplazaron aquellos topónimos por otros que reivindicaban la nueva ideología (más o menos democrática, según los casos) y la identidad que consideraban como propia (cultura y lengua).

En el caso español, García Álvarez (2009: 190) destaca como el Sexenio revolucionario, la II República, la Guerra Civil y la dictadura de Franco fueron períodos especialmente intensos en la imposición de una nueva memoria histórica, hecho reflejado por ejemplo en el cambio de la rotulación toponímica urbana. Las calles que reciben nombres de personas o de hechos vinculados a determinada ideología sufren a menudo las consecuencias de los avatares políticos, siendo sustituidos por otros más acordes cuando cambia la coyuntura política (Ruiz, 2002: 431).

Los estudios toponímicos con enfoque ideológico e identitario también abordan aspectos de raza y género (Alderman e Inwood, 2013), ya que el dominio político tradicional de los hombres de raza blanca ha impedido o minimizado la existencia de toponimia urbana referida a personas de otras razas y a mujeres (de cualquier raza). También son estudiados bajo el mismo enfoque otros fenómenos recientes como la mercantilización toponímica (Mitchelson et al., 2007; Light y Young, 2015): cada vez son más los nombres de lugar cuyos derechos son comprados y vendidos como mercancía, ya que son una forma de poder simbólico que crea distinción social entre las élites y el populacho y que puede transformarse en capital simbólico (Bourdieu, 1991; Rose-Redwood, 2008). Cabe señalar que la imagen de poder que generan los topónimos ha ejercido un rol notable en la promoción socioeconómica de ciertos lugares. Muchas de las urbanizaciones construidas durante las últimas décadas ignoran la toponimia tradicional y son bautizadas por sus promotores con un nombre supuestamente atrayente y seductor para el mercado (Panorama, Costamar, Costabella, El Pinar, El Jardín, etc.) (Tort, 2011).

Algunos autores consideran que el creciente peso del enfoque ideológico e identitario puede debilitar el interés por el análisis toponímico de aquellos territorios donde la mayoría de los nombres de lugar no fueron impuestos desde el poder (Whatmore, 2002: 533), como es probablemente el caso de Alicante, que analizaremos en el apartado de resultados y discusión. Antes de pasar a dicho 
apartado, dedicamos un apartado a las características de nuestro lugar de estudio y a la metodología seguida para el análisis de su topónimo.

\section{Caso de estudio y metodología}

a) El caso de estudio

El caso de estudio analizado en este artículo es el del topónimo Alicante (Alacant, en valenciano; Laqant, en árabe; LUCENTUM en latín). El primer Alicante consistía en un pequeño poblado, creado hacia el siglo IV a. C., que durante el dominio romano era conocido como LUCENTUM en latín. Las ruinas de este poblado, actualmente museizadas, se enclavan en el actual barrio alicantino de L'Albufereta y en lo alto del Tossal de Manises, a $38 \mathrm{~m}$ de altitud, cerca del mar. El poblado del Tossal de Manises fue abandonado hacia el siglo III d. C., y varios siglos después surgió un emplazamiento alternativo en la Medina Laqant o Vila Vella (casco antiguo) de Alicante, a unos cuatro kilómetros de distancia (figuras 1, 3, 4, 5 y 6).

En una primera aproximación sobre la repercusión de los Programas LEADER y PRODER en Andalucía en el periodo 2002-2008, lo primero que se constata es que su incidencia territorial ha sido muy extensa, ya que los GDR constituidos abarcan la mayor parte del territorio andaluz. Han quedado fuera de estos programas sólo los entornos más próximos a las capitales andaluzas (Cádiz, Huelva, Sevilla, Córdoba, Málaga, Almería, Granada y Jaén) y sectores del litoral mediterráneo de las provincias de Cádiz, Málaga, Granada y Almería.

La inversión total realizada fue de poco más de 928 millones de $€(\mathrm{M} €)$ de los cuales 347,64 millones (el 37,4\%) son los que se corresponden con las subvenciones concedidas y 580,47 millones (el 62,6\%) con la inversión privada realizada. Si se tiene en cuenta, a su vez, en estas cifras globales del conjunto de Andalucía, el tipo de destinatario y el empleo creado se acotan un poco más estos valores de conjunto. De este total de proyectos en poco más de una cuarta parte (el 25,13\%) ejercen como promotores los propios ayuntamientos (2.066 en valores absolutos) con inversiones que superan los $113 \mathrm{M} €$, correspondiendo más del $65 \%$ a subvención. Otro número importante lo conforman los promovidos por los propios GDR con 1.355 proyectos (el $16,48 \%$ del total) y una inversión de algo más de $104 \mathrm{M} €$, en su mayor parte correspondientes a subvenciones ( $88 \mathrm{M} €$ ) el $85 \%$ del total invertido.

Otra característica de este tipo de proyectos de "promoción pública" es el escaso empleo que generan, ya que para el conjunto de Andalucía y el periodo contemplado los ayuntamientos sólo han acumulado el 5,31\% de los empleos creados y los GDR el $1,64 \%$. Resulta evidente, a la luz de estas cifras, que en la promoción pública su objetivo principal no es la creación de empleo sino más bien la subsanación de deficiencias en materia de equipamientos e infraestructuras en el caso de los ayuntamientos, o la difusión-gestión en el caso de los GDR.

Si se suman los proyectos promovidos por los ayuntamientos y los propios GDR andaluces, estos suponen el $41,61 \%$ del total, siendo la subvención concedida a sus 
proyectos de $162 \mathrm{M} €$. Cantidad esta que representa casi la mitad de todas las subvenciones concedidas, concretamente el $46,6 \%$ del total.

De los datos anteriores se deduce claramente la importancia que "los promotores públicos" han tenido en la gestión e impulso del desarrollo rural andaluz. Aunque es indudable que las labores de promoción)difusión de las actividades del GDR, así como la dotación de infraestructuras y equipamientos por parte de los ayuntamientos influyen en la mejora de la calidad de vida de los habitantes de estos espacios rurales, y por ende en la permanencia de los mismos en estos espacios, no son pocos los autores (Hortelano y Martín, 1999; Navarro y Larrubia, 2000; Pillet y Santos, 2008) que cuestionan que el excesivo peso de este tipo de proyectos desvirtúan una de sus principales finalidades, el desarrollo económico, la mejora del tejido productivo y el acceso a la innovación y la diversificación empresarial.

Resulta evidente que la existencia de un buen equipamiento deportivo o cultural mejora la calidad de vida; y si para su construcción se recurre a este tipo de fondos es una opción correcta, pero quizás cabe preguntarse, también, si a través de estos recursos financieros se enmascaran unas cifras globales, que en el fondo, en una parte muy importante de las mismas, vienen a suplir la falta de inversión en las áreas rurales de otras administraciones en materias que son de su competencia, ya sean autonómica, provincial o estatal. En definitiva, los ayuntamientos como otro agente más del territorio acometen, ante la ausencia de iniciativa privada, lícitamente proyectos de interés social para cubrir necesidades colectivas locales que sus exiguos presupuestos impiden (Alario y Baraja, 2006: 290-1).

En cualquier caso, estas cifras globales a nivel de Andalucía, no hacen más que confirmar a nivel de comunidad autónoma lo que ya se había apuntado en otros estudios en ámbitos más reducidos como la provincia de Granada (Cejudo y Navarro, 2009) sobre la debilidad del tejido productivo regional y la concentración de los proyectos bien en los que hemos denominado "promotores públicos" bien en las sociedades mercantiles (en su mayor parte constituidas con anterioridad). Efectivamente, las empresas (ya sean anónimas o limitadas) llevan a cabo el 18,51\% de los proyectos (1.522), pero en cambio concentran el 38,90\% de la inversión comprobada (algo más de $361 \mathrm{M} €$ ) y casi la mitad de la inversión privada (algo más de 279 M€ que suponen el $48,15 \%$ del total invertido). La importancia de estas sociedades empresariales en relación con el empleo es evidente, pues concentran el $49,37 \%$ del empleo creado en el periodo analizado y el $46,56 \%$ del empleo consolidado. En relación con el empleo joven las cifras se sitúan en el mismo rango con un 50,78\% (2.424 absolutos) del total de esta categoría. De nuevo, los valores medios del conjunto de Andalucía están en la tónica de lo detectado en ámbitos provinciales (Cejudo y Navarro, 2012). 
Figura 1. Término municipal de Alicante con su área urbanizada y los principales hitos mencionados en este artículo.

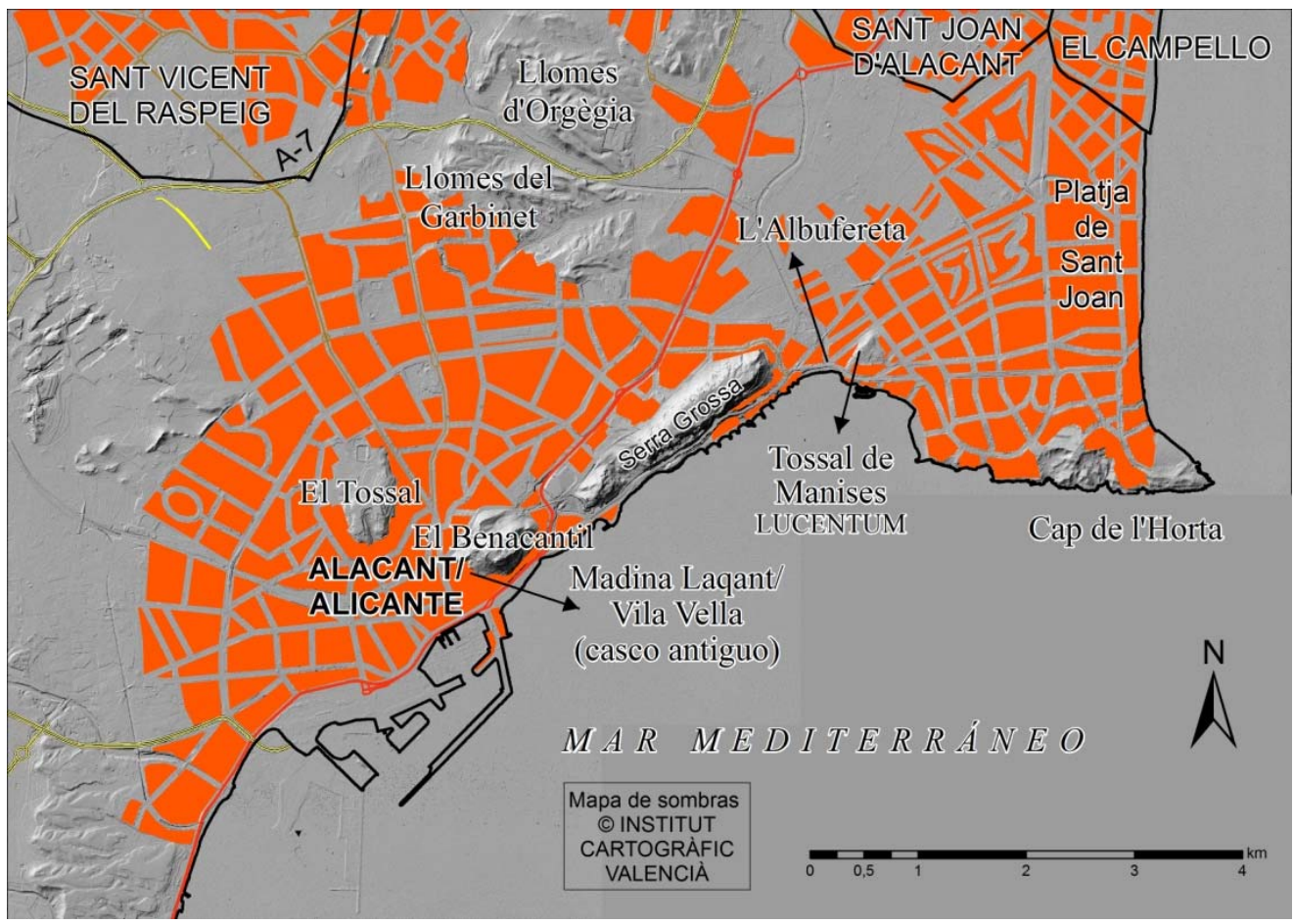

Fuente: Elaboración propia.

El actual municipio de Alicante cuenta con cerca de 330.000 habitantes, repartidos en algo más de $200 \mathrm{~km}^{2}$ (1.650 hab./ $\left.\mathrm{km}^{2}\right)$. Es la segunda ciudad más poblada del País Valenciano y la undécima de España. El área metropolitana de Alicante y Elche (Elx, en valenciano) supera los 700.000 habitantes y es la novena mayor del Estado.

En la figura 2 vemos, por un lado, el mapa de la izquierda, donde se muestra la distancia kilométrica en línea recta entre Alicante y las grandes ciudades de su entorno (hasta unos $400 \mathrm{~km}$ ). Entre estas últimas incluimos la fachada mediterránea ibérica (desde Barcelona hasta Almería), el interior peninsular (la Mancha y las depresiones del Guadalquivir y del Ebro), las Islas Baleares y también el norte de África. Cabe señalar que Alicante ha mantenido relaciones intensas con esta última área desde la Antigüedad (púnicos), pasando por la Edad Media (musulmanes), la época contemporánea (pied-noirs argelinos) y aún hoy en día (gracias al ferri que conecta Alicante con Orán). En el mapa de la derecha observamos la localización de Alicante en el tercio meridional del País Valenciano y al este de la Región de Murcia. 
Figura 2. Distancia en kilómetros (en línea recta) entre Alicante y las Principales ciudades de su entorno (izquierda) y localización de Alicante al sur del País Valenciano (derecha).

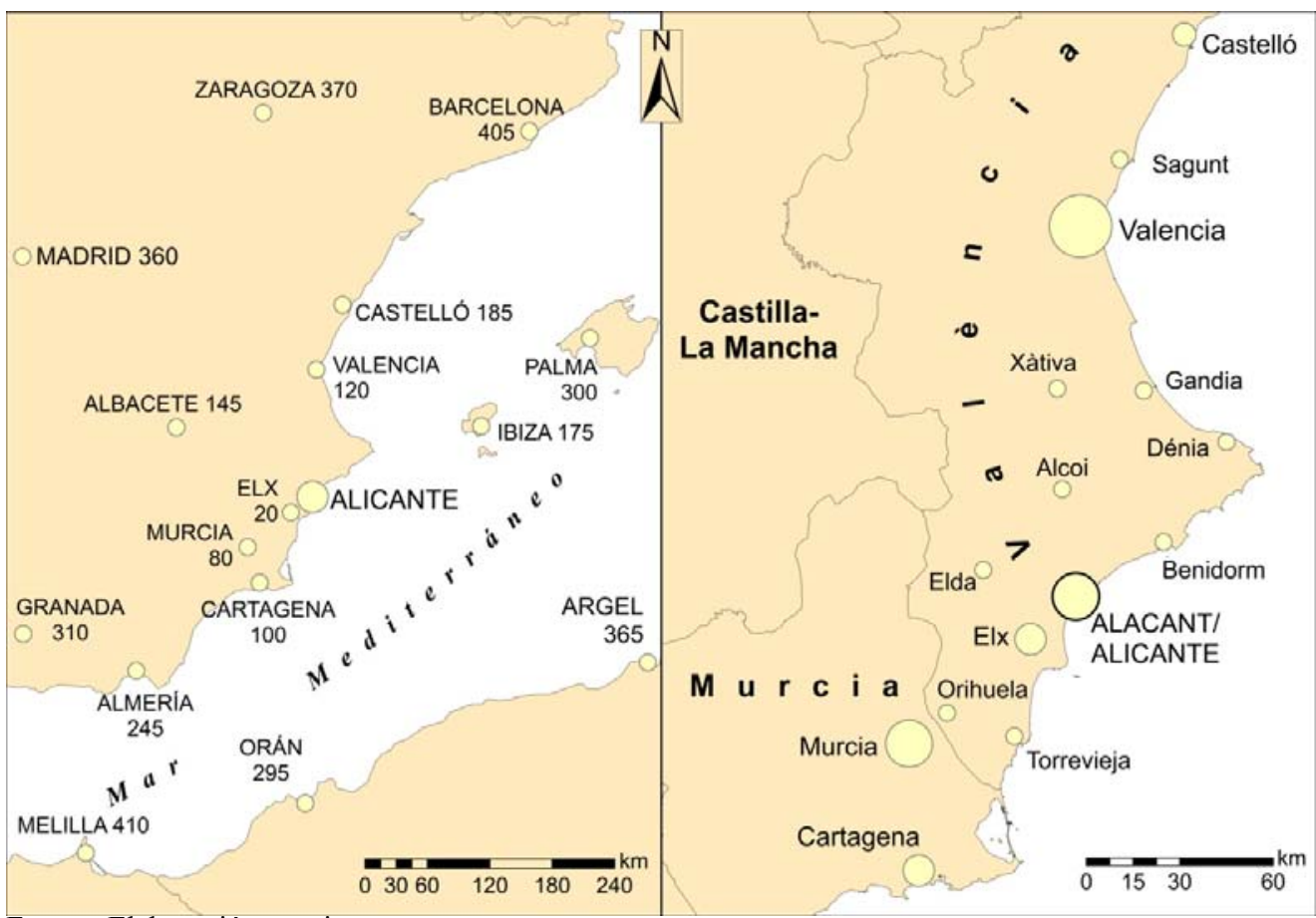

Fuente: Elaboración propia.

b) Metodología

Por lo que respecta a la metodología, para analizar el contenido semántico del topónimo Alacant/Alicante hemos llevado a cabo tres estudios paralelos: uno geográfico, otro histórico y un tercero, lingüístico. La síntesis de los tres análisis nos permite llegar a una hipótesis novedosa por lo que respecta al contenido semántico del topónimo en cuestión. Para ilustrar los resultados del análisis geográfico se ha elaborado un mapa (figura 3) que muestra una recreación de la probable geografía del Tossal de Manises en la Antigüedad; sobre este mapa se muestran los rasgos físicos más relevantes por su excepcionalidad de aquel emplazamiento. Por otro lado, se recalca el momento histórico crucial que fue el desplazamiento del núcleo urbano con su topónimo- desde su ubicación original (el Tossal de Manises) hasta el actual solar alicantino, a los pies del Benacantil. Dicho traslado se refleja también en un mapa (figura 5) donde se muestra el emplazamiento de LUCENTUM (Tossal de Manises), por un lado, y el del Laqant árabe y el Alacant/Alicante cristiano, por el otro. Por último, nos fijamos en las diferentes hipótesis que diversos lingüistas han formulado para explicar el complejo contenido semántico de Alacant/Alicante. No 
solo prestamos atención a la etimología de sus propuestas, sino también a si los rasgos geográficos que estas describen concuerdan con los del entorno del emplazamiento original alicantino. A continuación, lanzamos nuestra hipótesis lingüística basándonos en criterios paisajísticos (rasgos físicos sobresalientes), históricos (ubicación original) y etimológicos, comparando nuestra propuesta con otros topónimos similares del ámbito europeo occidental o meridional.

Para llevar a cabo los mapas mencionados hemos elaborado un modelo digital de elevaciones (MDE) basado en tecnología LIDAR, que data de 2009 y que hemos bajado gratuitamente desde la página web de Terrasit (Institut Cartogràfic Valencià). Una vez descargado el LIDAR del término municipal de Alicante, hemos procedido a confeccionar la simbología de las figuras 3 y 5 mediante el programa ArcGIS de ESRI, que también hemos usado para confeccionar las figuras 1 y 2.

\section{Resultados}

\subsection{Geografía de LUCENTUM/Alicante}

Para entender las motivaciones que pudieron conducir en la Antigüedad a la acuñación del topónimo que con el tiempo derivaría en el doblete (castellano y valenciano) actual de Alacant/Alicante, consideramos que hay que observar la ubicación geográfica del núcleo al que se asoció originalmente el topónimo en cuestión, esto es, el poblado llamado LUCENTUM por los romanos. Este yacimiento se halla en el Tossal de Manises, un pequeño cerro (tossal, en valenciano) donde debía de ser frecuente encontrar azulejos (manises) o, probablemente, restos cerámicos de épocas pretéritas procedentes de LUCENTUM. Junto a dicho tossal se encuentra L'Albufereta, una pequeña laguna (albufera es árabe y significa 'mar pequeña', o más bien 'laguna'; el sufijo - eta marca un diminutivo en valenciano) que fue desecada a mediados del siglo XX. Dicha laguna probablemente estuvo en la Antigüedad conectada con el mar abierto; por lo tanto, cabría hablar en aquel tiempo de una ensenada o cala, más que de una laguna o albufera. Así pues, el paisaje de LUCENTUM se correspondería con una pequeña elevación (tossal) junto a una cala o ensenada.

Hasta mediados del siglo XX L'Albufereta fue una laguna malsana que favorecía la propagación de infecciones como la malaria. Esta zona húmeda se hallaba en el tramo final del Barranc del Juncaret ('lugar de juncos'), donde confluyen los barrancos del Garbinet, Orgègia y Santa Faç. Si dicha insalubridad plurisecular se hubiese dado también entre el siglo IV a. C. y el II-III d. C., hubiera sido incompatible con el floreciente desarrollo que sabemos que conoció LUCENTUM en dicho periodo. Pero como hemos señalado, durante el auge de LUCENTUM, L'Albufereta no debía de existir aún como laguna, sino como una cala donde habían penetrado las aguas marinas (posiblemente ya desde finales del Terciario), lo cual habría hecho posible el comercio marítimo a los mismos pies del Tossal de Manises (figura 3) (Box, 1984: $52)$. 
Figura 3. Recreación del aspecto que debía tener la cala de L'Albufera en época antigua, a partir de los datos de Box (1984).

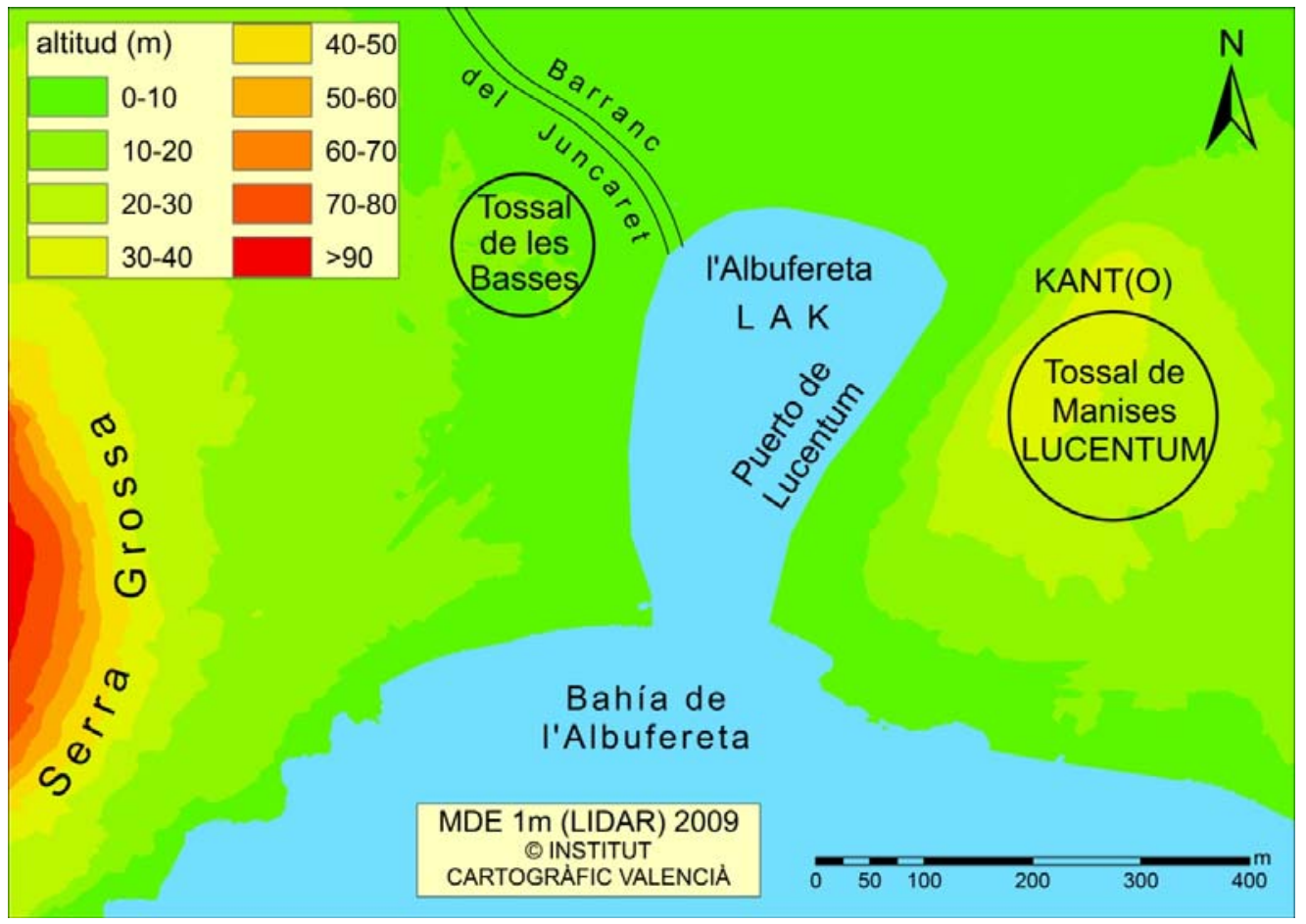

Fuente: Elaboración propia.

Parece ser que en época antigua L'Albufereta llegó a albergar sucesivamente -no a la vez- dos pequeños puertos: uno junto al llamado Tossal de les Basses, en el lado oeste de la ensenada que formaba L'Albufereta, y otro en el Tossal de Manises, en su lado este (figura 3). El mencionado Tossal de les Basses es un poblado ibérico del que se ha excavado un barrio portuario, datado entre los siglos V-IV a. C. Pocas décadas después, LUCENTUM (Tossal de Manises) le robó el protagonismo al poblado ibérico del Tossal de les Basses, cuyo declive estaría relacionado con un aluvionamiento de época tardoibérica (s. III a. C.) que impidió su comunicación marítima y, por tanto, acabó con la viabilidad del área portuaria (Rosser y Fuentes, 2007; Esquembre y Ortega, 2008).

Mientras tanto, el poblado del Tossal de Manises -fundado hacia el siglo IV a. C.perduró durante la dominación romana, viendo ampliado en ese tiempo el recinto fortificado original. El elemento clave del desarrollo de LUCENTUM durante el periodo romano fue su puerto a orillas de la cala de L'Albufereta y a los pies del Tossal de Manises, desde donde se exportaba vino, aceite, salazones, cereales y otros recursos agrícolas recolectados en el ager lucentino. Este recinto portuario entró en 
crisis entre el final del siglo II y el inicio del III d. C., debido al fin de las relaciones comerciales que habían sustentado el dinamismo económico de la ciudad (Olcina, 2005 y 2009).

Figura 4. Yacimiento de Lucentum en un entorno de edificios altos (barrio de L'Albufereta)

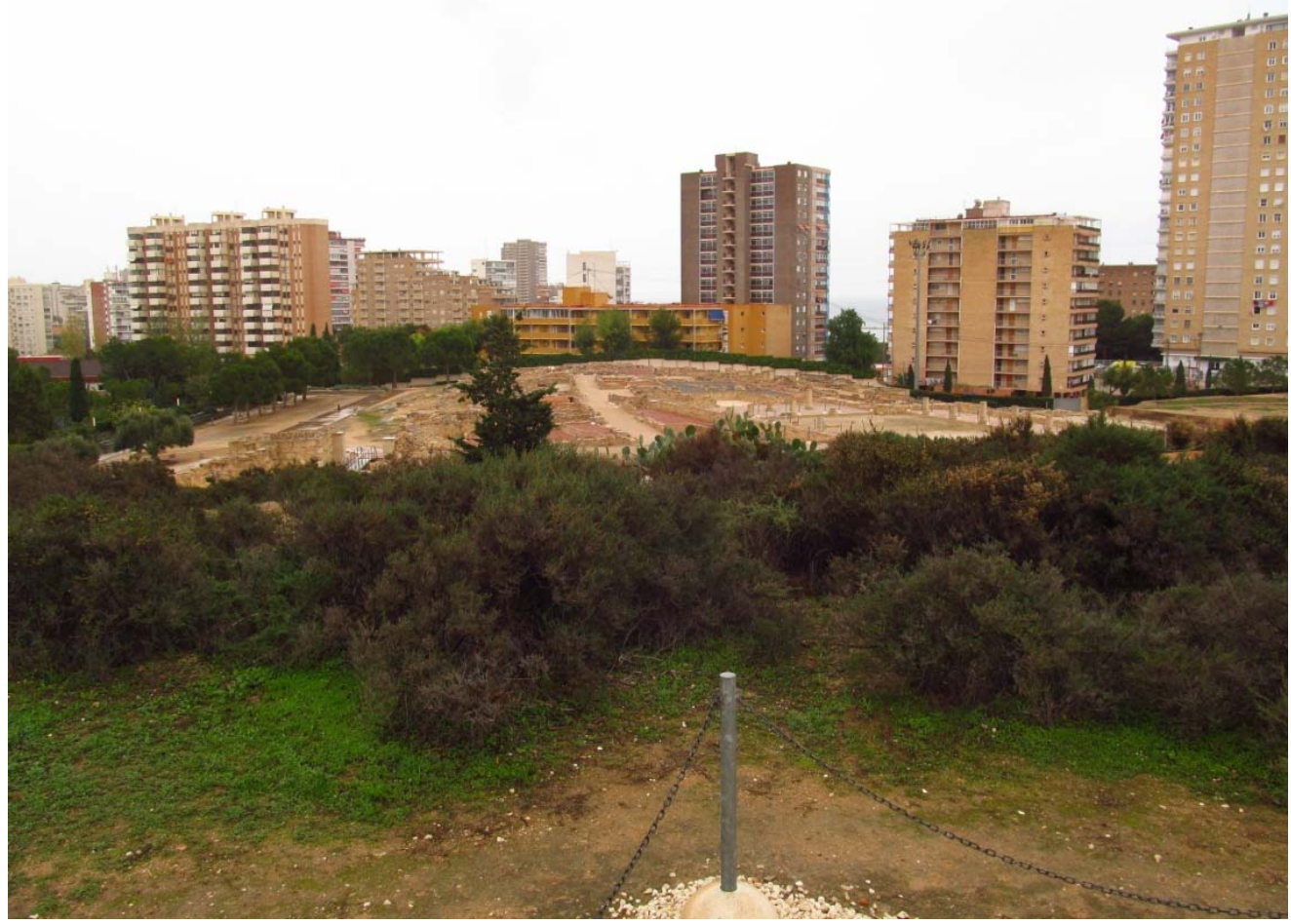

Fuente: Antoni Martínez i Bernat.

A la vez que se abandona el puerto, se despuebla también LUCENTUM. Aparte del declive comercial, pudo haber influido en ello un progresivo crecimiento de una restinga litoral que obstruyera los depósitos fluviales y conllevara el estancamiento de las aguas. Para dicho aluvionamiento debieron influir dos factores principales: la regresión del nivel del mar y la colmatación debida a aportes marinos $\mathrm{y}$, sobre todo, fluviales (Box, 1984: 52).

Seguramente, desde el principio de la dominación musulmana L'Albufereta debía de ser ya una zona poco plausible para ser habitada. Tal vez fue por eso por lo que se desechó entonces la posibilidad de instalarse en el Tossal de Manises y se decidió fundar la Medina Laqant a cierta distancia de este. L'Albufereta fue en época medieval y moderna una zona pantanosa e insalubre, con todos los perjuicios que ello 
acarreaba a sus moradores, susceptibles de contraer el paludismo (Box, 1984: 54). Un documento de 1510 ya describe dicha situación:

[...] ninguna persona privada o estranya no puga amerar lli, cànem ni altre esplet en l'Albufera de dita ciutat a prop de les heretats de Gaspar Bernat e d'en Antoni Merita i d'en Bernat Joan i de moltes altres per lo gran dany que hi ha de la infecció e males odors que donen [...] (que ninguna persona privada o extraña pueda empapar lino, cálamo ni otra cosecha en las haciendas cercanas a L'Albufereta de Alicante por el gran daño que hay en la infección y los males olores que generan)

Otro documento de 1703 (Alberola, 1989: 80) habla de los efectos nocivos derivados de la laguna:

[...] que les moltes enfermetats que este any han hagut en la partida de la Condomina embarassant casi les faenes de les heretats en gran dany dels amos d'aquelles i haver-se mort moltes persones [...] (las muchas enfermedades que este año (1703) ha habido en la partida de la Condomina (junto a L'Albufereta) casi comprometen los trabajos en las haciendas, con gran daño para sus propietarios y habiendo muerto muchas personas)

Tras varios intentos de desecación, el saneamiento definitivo de L'Albufereta se llevó a cabo a mediados del siglo XX. El entorno de LUCENTUM había estaba prácticamente vacío de construcciones hasta que dicha laguna fue desecada. $\mathrm{Su}$ saneamiento propició que, con el boom turístico en la década de 1960, se produjera una notable expansión urbana, que acabó por desvirtuar el entorno del muy interesante yacimiento romano de LUCENTUM (figuras 4 y 6 ).

\subsection{Historia de LUCENTUM/Alicante}

LUCENTUM (Tossal de Manises) es considerado por Llobregat (1969, 1970 y 1972) un yacimiento plenamente ibérico, mientras que otros autores (Olcina et al., 2010) lo consideran más similar a los poblados púnicos del norte de África que a los ibéricos de su entorno. Sea más o menos ibérico o púnico, LUCENTUM fue destruido a finales de la Segunda Guerra Púnica (circa 200 a. C.), y vivió un largo período de abandono hasta finales del siglo II a. C., momento de un nuevo episodio constructivo. A mediados del siglo I a. C. se inicia una nueva intervención edilicia y se produce una reestructuración del viario urbano. Durante la época de Augusto (27 a. C. -14 d. C.) la ciudad adquirió el rango de MUNICIPIUM, y pasó por ello a gobernarse autónomamente con instituciones romanas; es en ese momento cuando se atestigua por primera vez el topónimo LUCENTUM en las inscripciones y en los libros de historia. La ciudad mostró desde finales del siglo I a. C. y a lo largo del siglo I d. C. un período de cierto esplendor. Con el fin de este último siglo, sin embargo, se inició su decadencia, que culminó con el abandono definitivo y la desaparición de la ciudad en el siglo III d. C., por razones económicas internas y de dinámica regional (Olcina, 2005 y 2009; Frías, 2010; 147-149; Rosser, 2014: 1.601; Abad, 2015: 45-46). 
Figura 5. Traslado de la ciudad romana de LUCENTUM a su emplazamiento actual $(4 \mathrm{~km}$ al SO de aquella).

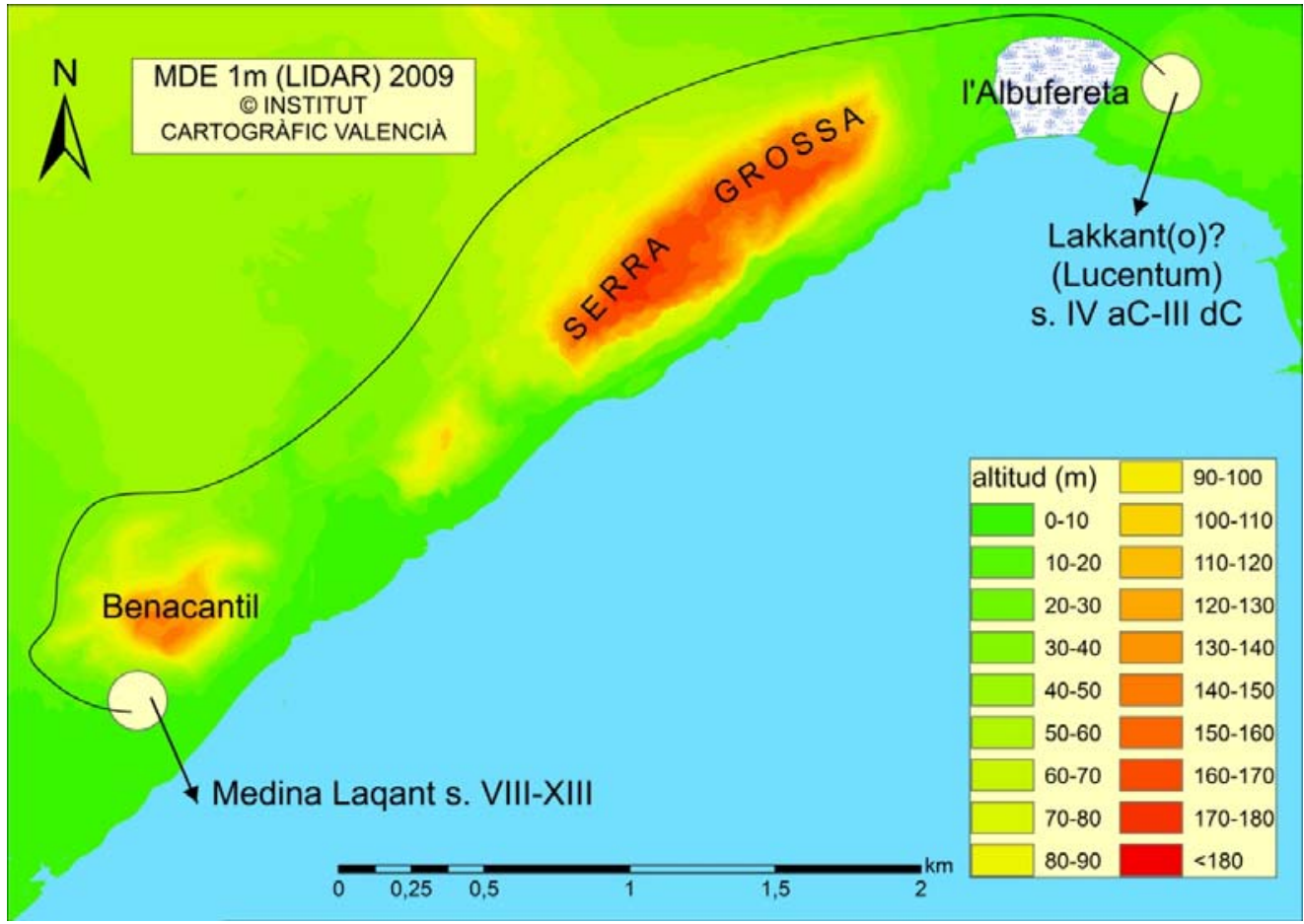

Fuente: Elaboración propia.

No se sabe con seguridad en qué momento se produjo el traslado de LUCENTUM desde su emplazamiento antiguo (el Tossal de Manises) hasta las faldas del Benacantil, donde hoy se halla la Vila Vella (casco antiguo) de Alicante, y anteriormente estuvo la Medina Laqant (figuras 5 y 6). Algunos autores consideran que fueron los árabes del s. IX quienes refundaron la ciudad en su actual ubicación sobre el monte Benacantil (Pérez y González, 2016: 14) y trasladaron allí su topónimo desde el Tossal de Manises. Otros, en cambio, apuntan que dicha refundación pudo haberse producido antes, de modo que el lugar llamado LQNT (Laqant) que aparece en el Pacto de Teodomiro -pacto que señala el momento a partir del cual los musulmanes iban a ocupar esta plaza- ya debía de estar habitado antes de la llegada de los árabes, y se encontraría en el mismo lugar donde había de surgir después la Medina Laqant (Roca y Rosser, 2003: 222) (figuras 5 y 6). 
Figura 6. Barrio de L'Albufera, Serra Grossa y Benacantil desde el Tossal de Manises.

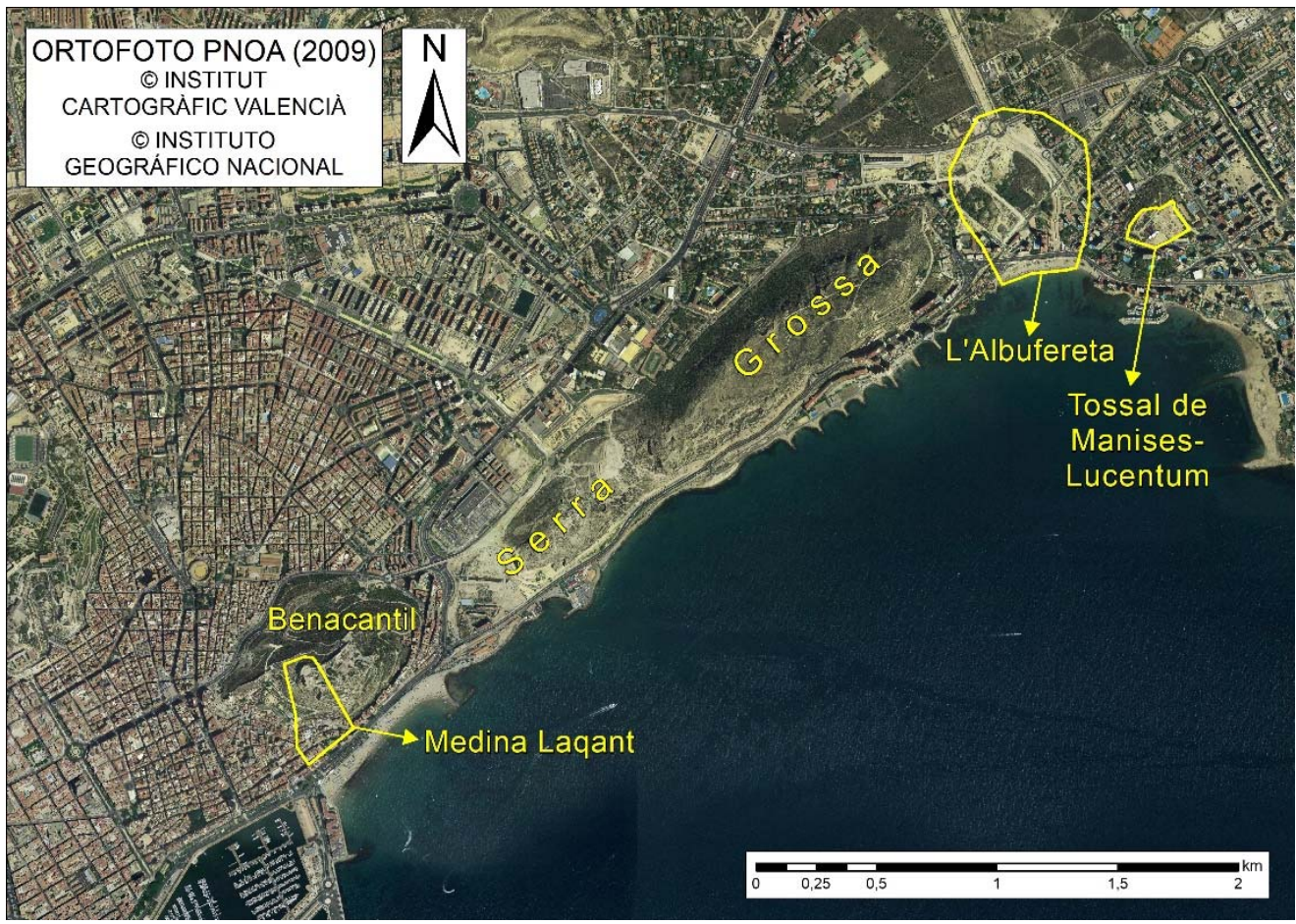

Fuente: Elaboración propia.

El abandono de ciudades históricas y su traslado -incluyendo el topónimo- a lugares más propicios para su refundación no es un hecho extraño. Ocurre, por ejemplo, en la segunda (Alacant/Alicante), la tercera (Elx/Elche) y la cuarta (Castelló de la Plana) ciudades valencianas. ILICI, antigua ciudad ibérica, luego colonia romana, y más tarde asentamiento bizantino y visigodo, había ocupado desde el siglo VII a. C. hasta el VII d. C. el actual yacimiento de l'Alcúdia. La conquista islámica supuso el abandono del mismo y su traslado - junto con su topónimo- a la medina de Ilš (Elx), 3 $\mathrm{km}$ al norte de l'Alcúdia, donde hoy se encuentra la ciudad histórica de Elche. Castelló fue un castillo árabe ubicado sobre un cerro (Tossal de la Magdalena) que, tras la conquista cristiana por Jaume I, fue trasladado desde el incómodo -aunque fácilmente defendible-Castelló del Sas ('de la montaña') y refundado sobre el más accesible llano aluvial, a solo $4 \mathrm{~km}$ de distancia, y por ello recibió el nombre de Castelló de la Plana ('del llano'). Otro ejemplo similar lo encontramos en Elda (comarca del Vinalopó Medio), que surgió en el yacimiento iberorromano del Monastil (s. V a. C.), sobre un cerro, y que fue abandonada progresivamente con la decadencia comercial del Imperio Romano, y luego trasladada al valle eldense (Valle del Vinalopó) (Membrado-Tena e Iranzo-García, 2017, 201-202). 


\subsection{Etimología de Alicante}

En la forma actual del doblete toponímico AlicantelAlacant se detecta la influencia del árabe, que añadió a la forma también árabe Laqant el prefijo al- (artículo), dando como resultado Al-lacant, topónimo que encontramos en el Atlas Catalán (1375) de Abraham Cresques (Rosselló, 1998: 108), y que acaba simplificándose en Alacant, en catalán/valenciano; en Alicante, en castellano; y a veces en la forma mixta Alicant (Herrero, 1984: 10-11). La forma castellana parece fruto de una disimilación para evitar la doble repetición del sonido $a$, o tal vez derive de una forma árabe dialectal *Leqant (Mira, 2006: 138) o *Liqant (Herrero, 1984: 9) -cuya pronunciación habría convivido junto con la del árabe clásico Laqant- y que pudo haber sido fruto de la imela árabe.

La forma árabe Laqant, que encontramos en varios textos de geógrafos árabes como al-Bakri (s. XI), al-Idrīsī (s. XII), Yāqūt (s. XII-XIII) y al-Magribī (s. XIII) (Hinojosa, 1986; Sánchez y Alonso, 2003-2004), no es fácil de explicar cómo derivaría de la latina LUCENTUM. Si bien Barceló (2010: 30) y Galmés (2000: 165) sí consideran plausible dicha evolución por influencia del árabe, Coromines (1972: 277; 1974: 163-4) piensa, en cambio, que si LUCENTUM (pronunciado /lu'kentum/ en latín clásico) hubiera sido la única forma existente en las épocas romana y visigoda, el sonido $/ \mathrm{k} /$ se hubiera palatalizado antes del siglo VIII, y los hablantes de árabe que dominaban la zona a finales de esa centuria no hubiesen podido recuperar el sonido /k/ conservado en Laqant.

Siguiendo este último razonamiento, Laqant podría explicarse como continuación de un topónimo usado antes de los romanos y que nunca se habría perdido entre la población autóctona (Nieto, 1997: 46), a pesar de que durante el periodo romano se acunase una forma latinizada del mismo, LUCENTUM (que puede relacionarse con el participio presente, LUCENTEM, del verbo LUCEO, 'brillar, iluminar'). LUCENTUM podría ser, por lo tanto, una adaptación al latín de un topónimo prerromano. La adaptación a la lengua nueva en el territorio se produce mediante la reinterpretación de un topónimo preexistente y no transparente de manera que parezca tener un significado en la lengua de quienes llevan a cabo la adaptación (cf. Morala, 1994: 6769).

Así, para Coromines (1989-1997, II: 51-52), LUCENTUM debió de ser una latinización, poco exitosa entre los autóctonos, de una forma prerromana, pero al mismo tiempo existiría en el habla local y popular hispanolatina una variante alternativa, variante que fue la adoptada en su momento por los hablantes de árabe; LUCENTUM sería en cambio un topónimo formal usado solo por las capas más cultas, y desaparecido tras el fin del dominio romano. No existen, con todo, testimonios históricos de la forma popular de donde según esta teoría derivaría Laqant, ya que los tratadistas grecolatinos solo atestiguan el topónimo LUCENTUM (Plinio el Viejo) y

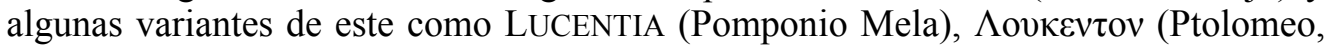
adaptando la forma latina al griego), [MUNICIP(IUM)] LUCENTINA (en el CORPUS INSCRIPTIONUM LATINARUM, II: 4379 y 5958), LUCENTES y LUCENT(INUM) 
(Anónimo de Ravenna, IV: 42-304, 14 y V: 3-343-5) (Herrero, 1984: 8; Rosser, 2014: 1.601).

Tal vez LuCENTUM, 'luminoso', fuese una traducción libre al latín de $\kappa \rho \alpha$ $\Lambda \varepsilon v \kappa \quad$ (Akra Leuké) o de $\Lambda \varepsilon v \kappa \quad \kappa \rho \alpha$ (Leuké Akra), 'fortaleza blanca', topónimo griego que designa una base militar fundada en 231 a. C. por el cartaginés Amílcar Barca, e identificada por muchos autores con el posterior municipio romano de LUCENTUM, aunque otros la ubican en Carmona (Sevilla) (García-Bellido, 2010: 203205). En la obra BIBLIOTHECA HISTORICA del historiador griego Diodoro (XXV: 10, 3, 12) se cita Leuké Akra, así como en el AB URBE CONDITA de Tito Livio (XV: 14) es citado CASTRUM ALBUM ('fortaleza blanca'), aunque no se sabe con certeza si podría referirse también a Leuké Akra (Herrero, 1984: 8).

Compartimos la opinión de Coromines de que el árabe Laqant no parece proceder de LUCENTUM. Vemos poco plausibles, sin embargo, las fórmulas que este y otros autores han empleado para reconstruir el topónimo prerromano que su teoría presupone. Coromines (1976, I: 48-49) considera que el nombre prerromano y conservado en el habla popular sería *LEUKANTO, pero no explica su origen (si bien parece que se pueda relacionar con la palabra griega $\Lambda \varepsilon v \kappa$ /Leuké) (García-Sánchez, 2007: 93). Coromines afirma que los navegantes africanos o árabes que avanzado el siglo VIII ocuparon definitivamente la cora de Tudmir adoptaron el topónimo *LEUKANTO- directamente de la población hispánica, o tal vez a través de los griegos bizantinos que habían ocupado durante los siglos VI y VII las tierras del sureste peninsular.

Epalza (1994: 38) sugiere que la etimología última de Alacant es *Ilu-kant ('la ciudad del acantilado'), topónimo modificado en latín como LUCENTUM, pero fosilizado por los árabes como Laqant. Este origen es plausible desde el punto de vista geográfico, ya que LUCENTUM era una ciudad ubicada sobre un acantilado o, al menos, sobre un cerro. Además, desde el punto de vista filológico, hay mayor afinidad entre las formas *Ilukant y Laqant que entre LUCENTUM y Laqant, si bien la $i$ inicial de *Ilukant es un elemento distorsionador.

Mira (2006: 140) propone otra teoría que relaciona el topónimo Alacant, a partir de un origen lingüístico común ibérico-tartésico-vasco, con *ala 'llano, *can 'monte' $\mathrm{y} * t$ aumentativo, traducible por 'el llano del monte alto'. Esta teoría es poco probable desde el punto de vista histórico, ya que Mira identifica dicho 'monte alto' con el Benacantil (el solar actual de Alicante) y no con el Tossal de Manises (su solar antiguo); también es improbable desde el punto de vista geográfico, porque ni el Alacant original (el del Tossal de Manises) ni el medieval (el sito en la ladera del Benacantil) están sobre un llano. Además, la $a$ inicial de Alacant debió de ser aglutinada al topónimo en tiempo de los árabes, y por lo tanto no debía de existir en el momento de su acuñación. Durante la Edad Moderna, en el Tesoro de la lengua castellana, o española (1611), estudiado por González (2002), el padre Covarrubias confundió Alicante con ILLICI (Elx, $25 \mathrm{~km}$ al sur de aquella ciudad) y con ALONE (probablemente la Vila Joiosa, $35 \mathrm{~km}$ al norte). Unos pocos años antes, Guadix (c. 1593: 75), en su Diccionario de arabismos, hace derivar ALACANT del arábigo ALA, 
'sobre, SUPRA', y de CANT 'piedra o peña'; de manera que significaría 'sobre piedra' o 'sobre peña', y lo considera razonable ya que el castillo de Alacant se encuentra sobre la peña del Benacantil. A pesar de su antigüedad, una parte de la hipótesis de Guadix coincide con la expuesta en este artículo.

Más que *Ilukant o *Leukanto, proponemos una forma hipotética del topónimo

prerromano *Lakkant(o), de donde podría proceder sin dificultad alguna el Laqant árabe que origina la forma actual Alacant/Alicante. El topónimo *Lakkant(o) puede analizarse como un compuesto de los morfemas *lak y *kant(o), respectivamente 'la cala (agua estancada)' y 'el alto'. Significaría, pues, algo como 'el alto de la cala'. Veamos a continuación ambos morfemas por separado.

\subsubsection{Etimología de *lak}

En varias lenguas indoeuropeas existen topónimos que parten de una raíz *lak (latín

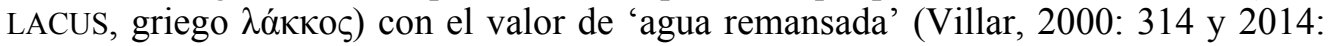
352 ), en referencia a un lago o una laguna, a un cauce ancho de un río (normalmente vadeable) donde se estanca el agua, o un mar de aguas quietas (normalmente una cala o una ensenada).

Entre los topónimos paleohispanos formados con *lak cabe mencionar el río LACCA o Wadilakka, que se correspondería con el río Guadalete, el cual posee una amplia zona marismeña cerca de su desembocadura, y en cuyas proximidades tuvo lugar la célebre batalla entre musulmanes y visigodos del año 711; Guadalete sería la forma moderna de un topónimo anterior relacionado con LACCA y que es citado por fuentes cristianas de los siglos XIII-XVII como Guadalec, Guadalaque, Guadalac o Bedalac (Chic, 1979-1980: 257).

LACIMURGA (Untermann, 1998: 81) o LACONIMURGI (Rubén, 2004) se identifica con el Cerro Cogolludo, en el término extremeño de Navalvillar de Pela; podría tratarse de un topónimo tautológico, ya que tanto LACI como MURGA parecen significar 'laguna, estanque': la primera derivaría de *lak y la segunda del elemento indoeuropeo $*_{m r g}$ o $*_{m r k}$ (Silgo, 2013: 196). LACIMURGA dominaba un paso estratégico que vadeaba el Guadiana, en una zona baja de vega que hoy se encuentra en parte sumergida por el embalse de Orellana.

LACCURIS se corresponde probablemente con Alarcos (Ciudad Real) (Silgo, 2013: 198), y podría referirse al río Guadiana que allí se ensancha y remansa y es fácil de vadear. LACIPO se halla en Casares (Málaga), donde el río Genal se ensancha y crea una zona pantanosa fácilmente vadeable. En LACOBRIGA (Carrión de los Condes, Palencia), el río Carrión también se ensancha, circunstancia que aprovecha el histórico Camino de Santiago para vadearlo. Lagos es el nombre actual de la histórica LACOBRIGA (Algarve), cuyo topónimo actual describe la geografía lacustre del área. Los LACETANI (pronunciado Laketani) eran una tribu ibera que probablemente ocupaba la parte central de la actual Catalunya, aunque desconocemos a qué área geográfica y a qué fenómeno hídrico pueda hacer referencia el *lak con que se inicia este topónimo; algunos autores defienden que el gentilicio catalán y el topónimo 
Cataluña podrían derivar de una metátesis de *Laketan y *Laketania, respectivamente (Coromines, 1989-1997, III: 336-337).

Fuera de Iberia, pero aún en el Mediterráneo, son diversos los topónimos griegos formados con *lak, algunos de los cuales describen calas o ensenadas de aguas marinas tranquilas: Lakka $(\Lambda \alpha ́ k \kappa \alpha)$, en la isla de Paxos (junto a Corfú); Lakkos

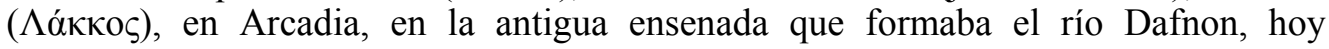

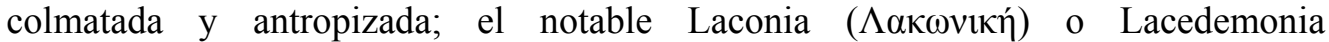
$(\Lambda \alpha \kappa \varepsilon \delta \alpha i ́ \mu \omega v)$, región al sur del Peloponeso donde se encuentra Esparta, y donde las costas recortadas dibujan numerosos entrantes de aguas remansadas. Lacydon $(\Lambda \alpha \kappa v \delta \omega ́ v)$ es el nombre de la profunda cala (actual Vieux-Port o Pòrt Vièlh) donde se establecieron los griegos foceos de Massalia (Marsella), estratégicamente protegida en dos de sus tres lados (Morel, 2006: 365).

Aunque no se puede descartar que la forma *Lakkant(o) sea la suma de *lakka (cala), más un formante $-n t(o)$, parece más probable que provenga de la aglutinación de *lak+*kant(o).

\subsubsection{Etimología de *kant(o)}

Las distintas teorías aquí mencionadas sobre el origen prerromano del topónimo Alacant/Alicante parecen coincidir - $\mathrm{O}$ al menos hay cierta afinidad- en el contenido semántico de su segundo morfema: -cant(e), que provendría de *kant(o).

Por lo que respecta a la raíz *kanto/a, su sentido es fluctuante de una lengua indoeuropea a otra, e incluso dentro de una misma lengua (Villar, 1990: 381). *Kanto/a presenta varias acepciones solo relacionables con un sentido muy vago de carácter oronímico, que ha originado numeroso léxico en castellano (canto, cantera, cantero, cantil, acantilado, cantón, etc.) y también, aunque no tanto, en catalán (cantal, cantalar, cantó, cantonada). Bertoldi (1931: 174) pensó que el galolatín cantus procedía de un sustrato cántabro-pirenaico (o paleovasco); Tovar (1955: 18-19) consideraba *kanto/a una voz propia del indoeuropeo occidental; y Coromines (1954, p. 643-644) le atribuía un posible origen celta, hipótesis a la que se adhirió Pokorny (1959: 525-36). Según Galmés (1983: 410) kanto posee una raíz celta con significado de 'piedra, guijarro' o de 'orilla pedregosa'.

La variabilidad del contenido semántico de *kant(o) y *kant(a) es notable, aunque siempre posee un significado oronímico, igual que el también variable *lak siempre lo tiene hidronímico. Los topónimos en *kantā presentan generalmente valor de 'piedra, roca' o de 'montaña, altura'. El pueblo de Cantavieja (Maestrazgo aragonés) se alza imponente sobre una roca casi vertical. Cantabria es una región abrupta gran parte de la cual también es conocida modernamente como La Montaña. Chantepierre (Bretaña) y Chanteroc (Alto Loira) parecen compuestos tautológicos ('la piedra de la piedra') desarrollados al desaparecer el uso de *kantā como apelativo en la correspondiente lengua. Cantalapiedra (provincia de Salamanca) también parece designar un topónimo tautológico derivado de *kantal, forma abundante tanto en topónimos como en nombres comunes (en catalán un cantal es una 'piedra gruesa'; en vasco, un kantal o 
kandal es una 'roca, piedra gruesa'; en Auvernia Cantal es el nombre de un macizo montañoso) (Villar, 1990: 385). Cantú es una ciudad lombarda y, por tanto, galoitálica, en la zona prealpina del llano padano. Aparte de los ejemplos citados, nos encontramos con otro posible topónimo tautológico derivado de *kant(o) como es Benacantil, que podría ser la 'peña de la peña' (de PINNA + cantil) (Coromines, 19891997, II: 51-52).

Galmés (1983: 410) analiza diversos topónimos mallorquines derivados de *kant $(o)$ - con la terminación masculina $o$, que cae en catalán - y que son parónimos de Alacant: Calicant (Alcúdia, Petra y Sant Llorenç des Cardassar) y Gallicant (Campos), al que podríamos añadir un Gallicant cercano a Reus y otro no lejos de Granollers, el Galligants gerundense, diversos Calicanto del interior de Valencia, así como el aragonés Gallocanta. Estos topónimos parecen tautológicos y compuestos por el elemento celta *kal(l)io 'piedra' (cf. francés caillou 'piedra'; cf. topónimos Callosa de Segura y Callosa d'en Sarrià, donde Callosa: 'pedregosa') más el ya referido elemento *kant $(o)$.

\section{Discusión}

Como hemos visto, varios autores coinciden en que para explicar la forma árabe Laqant es necesario presuponer la existencia de una forma prerromana no documentada de la que provendrían tanto Laqant como LUCENTUM. Para la reconstrucción hipotética de dicha forma prerromana se han propuesto varias alternativas: *Leukanto, *Ilukant, *Ala+kan+t. Nuestro propósito en este artículo es añadir a estas una nueva hipótesis de reconstrucción que nos parece que presenta la ventaja respecto a aquellas de adecuarse mejor a los hechos histórico-geográficos conocidos o probables. Según nuestra hipótesis, la forma prerromana de la que derivan las varias formas históricas que presenta el topónimo de la ciudad alicantina sería *Lakkant(o), con el significado de 'el alto de la cala'. Se trataría, así pues, de un topónimo que describiría rasgos geográficos sobresalientes del paraje donde se ubicó la que podemos considerar como la primera ciudad de Alicante, es decir, la antigua LUCENTUM: una ensenada o cala (hoy albufera desecada) y un alto o cerro (el Tossal de Manises).

Desde el punto de vista histórico-lingüístico, podemos señalar que nuestra hipótesis utiliza para la reconstrucción de la forma prerromana que habría dado origen a Alacant/Alicante dos radicales que se encuentran ampliamente representados en la toponimia de la Antigüedad tanto de las áreas hispánica y gálica como del mundo mediterráneo: *lak y *kant(o). Puede objetarse que ambos radicales parecen vincularse a lenguas indoeuropeas, mientras que los fundadores del LUCENTUM que existió entre los siglos IV a. C. y II d. C. no parece que perteneciesen -ya fuesen iberos o púnicos- a un pueblo cuya lengua se englobase en dicho grupo. Sí que pudieron, con todo, heredar y hacer suyo un topónimo preexistente para el lugar, del mismo modo que habían de hacer más tarde otros pueblos muy distintos llegados sucesivamente al territorio alicantino a lo largo de los siglos. 
Puede sorprender que pretendamos explicar mediante radicales relacionables con las lenguas indoeuropeas un topónimo de un territorio en el cual no tenemos atestiguada la presencia de población indoeuropea anterior a los romanos. Cabe señalar, sin embargo, que según Villar y Fernández (2001: 281) "carece de fundamento cualquier intento de división de la Hispania prerromana en dos áreas, una de las cuales hubiera permanecido virgen de indoeuropeidad hasta la llegada de los romanos", y de hecho son numerosos los topónimos de la zona de la Hispania antigua tradicionalmente considerada como no indoeuropea que, sin embargo, Villar (2000) explica a partir de elementos léxicos indoeuropeos. Autores como Coromines (1972: 246), Villar (1995: 511), Untermann $(2001,190)$ y Urkola $(2010,20)$ consideran que el proceso de indoeuropeización de la Península Ibérica debió de ser mucho más complejo y dilatado en el tiempo de lo que se ha venido suponiendo.

\section{Consideraciones finales}

A nuestro entender, desde el campo de la Geografía no se ha prestado, hasta el momento, toda la atención que merece al análisis de los nombres de lugar. No hay que olvidar que la Toponimia es una ciencia esencialmente geográfica: cada topónimo se refiere necesariamente a un lugar -a una parcela de espacio dentro de la superficie terrestre. Sin lugares en el espacio no habría nombres de lugar. Y la Geografía es la ciencia que estudia el espacio habitado y por lo tanto sus lugares, cada uno de los cuales recibe un nombre. Además, la Toponimia le es muy útil a la Geografía, ya que contribuye a la reconstrucción de los paisajes históricos: el análisis de los nombres de lugar ayuda a entender la evolución de un paisaje secular que ya no existe. Así pues, la toponimia puede y debe ser objeto de estudio geográfico.

Desde la Geografía todavía no existe una corriente masiva de autores que profundice en el análisis toponímico, si bien es cierto que cada vez más personas geógrafas abordan esta temática. Algunas se limitan a analizar topónimos transparentes. Algunas otras, menos, profundizan en la toponimia fósil o relicta, como en este artículo hacemos con el topónimo Alicante. Sin embargo, la Geografía -como la Toponimia- es una disciplina compleja y de convergencia, capaz de analizar los fenómenos físicos y humanos, estudiar sus sinergias e integrarlos: esta capacidad de análisis y síntesis dota a la Geografía de un atractivo y una originalidad indudables.

Frente a otras ciencias más especializadas, el carácter multidisciplinar de la Geografía supone un estímulo para abordar conceptos tan complejos como los nombres de lugar, que forman parte de la dimensión natural y, a la vez, de la cultural. Los geógrafos tienen mucho que aportar a la ciencia toponímica, ya que su visión analítica y a la vez sintética de los fenómenos espaciales los hace especialmente aptos para abordar el estudio de los nombres de lugar. Con el complejo análisis toponímico de Alicante, hemos querido contribuir a dicho propósito. 


\section{Bibliografía}

Abad, L. (2015): Identidades culturales en el sureste de la Península Ibérica. En: García, J., Mañas, I. y Salcedo F. (ed): Navigare necesse est. Estudios en homenaje a José María Luzón Nogué. Madrid, Universidad Complutense, 41-48.

Alberola, A. (1989): La bonificación de enclaves insalubres en el País Valenciano durante la Edad Moderna: el ejemplo de la laguna de la Albufereta (Alicante). Investigaciones geográficas, 7, 69-82.

Alderman, D. H. e Inwood, J. (2013): Street naming and the politics of belonging: spatial injustices in the toponymic commemoration of Martin Luther King, Jr.. Social and Cultural Geography, 14-2, 211-233. http://dx.doi.org/10.1080/14649365.2012.754488

Algeo, J. y Algeo, K. (2000): Onomastics as an interdisciplinary study. Names, 48, 3-4, $265-$ 274. http://dx.doi.org/10.1179/nam.2000.48.3-4.265

Barceló, C. (2010) : Noms aràbics de lloc. Valencia: IIFV-Bromera.

Bertoldi, V. (1931): Problèmes de substrat, Bulletin de la Société Linguistique de Paris, XXXII, 93-184.

Bourdieu, P. (1991): Language and Symbolic Power. Cambridge, Harvard University Press.

Box, M. (1984): El saneamiento del barranco de la Albufereta: tentativas en el siglo XX. Investigaciones geográficas, 2, 51-62.

Cela, C. J. (1998): Diccionario geográfico popular de España: introducción a la dictatología tópica. Madrid: Noesis.

Chic García, Genaro (1979-1980): Lacca. Habis, 10-11, 255-278.

Coromines, J. (1954): Diccionario crítico etimológico de la lengua castellana. Berna: Francke.

Coromines, J. (1965): Introducció a l'estudi de la toponímia catalana. Estudis de Toponímia Catalana, I. Barcelona: Barcino, 3-70.

Coromines, J. (1972): El libro de Schmoll sobre las lenguas hispánicas prerromanas. En Tópica hespérica: estudios sobre los antiguos dialectos, el substrato y la toponimia romances. Madrid: Gredos, II, 236-282.

Coromines, J. (1974): Elementos prelatinos en las lenguas prelatinas hispánicas. En Jordà, F., De Hoz, J. y Mitxelena, K. (ed.): Coloquio sobre lenguas y culturas prerromanas de la Península Ibérica. Salamanca, 84-164.

Coromines, J. (1976): Entre dos llenguatges. Barcelona: Curial.

Coromines, J. (1989-1997): Onomasticon Cataloniae. Els noms de lloc i noms de persona de totes les terres de llengua catalana. Barcelona, Curial Edicions Catalanes y La Caixa, 8 vol. Covarrubias, S. (1611): Tesoro de la lengua castellana, o española. Imprenta Luis Sánchez.

Davidson, J., Bondi, L. y Smith, M. (2005): Emotional geographies. Aldershot: Ashgate.

Dauzat, A. (1971): La toponymie française. París: Payot.

Dorion, H. (1984): Les relations entre la toponymie et les autres sciences sociales. En 450 ans de noms de lieux français en Amerique du Nord. Québec: Les Publicacions du Québec, 103-108.

Epalza, M. (1994): Les ràpites islàmiques i la toponímia catalana. Societat d'Onomàstica, Butlletí Interior, LVII, 35-47.

Esquembre, M. A. y Ortega, J. R. (coord.) (2008): Surcando el tiempo. Un barco de terracota de época ibérica (Tossal de les Basses, Alicante). Alicante: MARQ. 
Frías, C. (2010): El poblamiento rural de Dianium, Lucentum, Ilici y la ciudad romana de La Vila Joiosa (siglos II a. C.-VII d.C.). Alicante: Publicaciones de la Universidad de Alicante.

Fuchs, S. (2015): History and heritage of two Midwestern towns: a toponymic-material approach. Journal of Historical Geography, 48, 11-25. http://dx.doi.org/10.1016/j.jhg.2015.01.003

Galmés, Á. (1983): Toponimia balear y asociación etimológica. Archivum, XXXIII, 409-420.

Galmés, Á. (2000): Los topónimos: sus blasones y trofeos (la toponimia mítica). Real Academia de la Historia.

García-Álvarez, J. (2009): Lugares, paisajes y políticas de memoria: una lectura geográfica. Boletín de la Asociación de Geógrafos Españoles, 51, 175-202.

García-Bellido, M. P. (2010): ¿Estuvo Ákra Leuké en Carmona?. Palaeohispanica, 10, 201218.

García-Sánchez, J. J. (2007): Atlas toponímico de España. Madrid, Colección Bibliotheca Philologica, ed. Arco/Libros, 1-407.

Georgiou, V. (2010): Competing discourses in the debate on place names in Cyprus. Journal of Language \& Politics, 9-1, 140-164. http://dx.doi.org/10.1075/jlp.9.1.07geo

González, Y. (2002): El léxico toponímico en el Tesoro de Covarrubias. En Esparza, M. Á., Fernández, B. y Niederehe, H.-J. (eds.), Estudios de Historiografía Lingüística, III Congreso Internacional de la Sociedad Española de Historiografía Lingüística, Vigo, 2001. Hamburgo: Helmut Buske Verlag, II, 861-876.

Guadix, D. (c. 1593): Diccionario de arabismos: recopilación de algunos nombres arábigos. Estudio preliminar y edición M Á Águeda Moreno Moreno; prólogo Ignacio Ahumada, Jaén: Universidad de Jaén, 2007.

Hernández, C. (1994); Topónimos mayores y menores: y cuestiones conexas. En Álvarez, A. y Perdiguero, H. (eds.), Toponimia de Castilla y León, Actas de la reunión científica sobre toponimia de Castilla y León, Burgos, 1992, 81-92.

Herrero, A. (1984): Toponimia premusulmana de Alicante a través de la documentación medieval (II). Anales de la Universidad de Alicante. Historia Medieval, 3, 7-56.

Hinojosa, J. (1986): El puerto de Alicante durante la baja Edad Media. Anales de la Universidad de Alicante. Historia Medieval, 4-5, 151-166.

Jordan, P. (2012): Place names as ingredients of space-related identity. Names and Identities, 4-2, 117-131. https://www.journals.uio.no/index.php/osla/article/view/314

Kearney, A. y Bradley, J. J. (2009): Too strong to ever not be there: place names and emotional geographies. Social and Cultural Geography, 10, 77-94. http://dx.doi.org/10.1080/14649360802553210

Kremer, D. (2010): Toponimia de España - Toponomástica en España. En Gordón, M. D. (coord.), Toponimia en España. Estado actual y perspectivas de la investigación, Patronymica Romanica, 24, Gotinga: De Gruyter, 5-29.

Lapesa, R. (1972): La Toponimia como herencia histórica y lingüística. Madrid: Coloquio sobre Toponimia, Asociación Española para el Progreso de las Ciencias, 1969, 9-23.

Light, D. y Young, C. (2015): Toponymy as Commodity: Exploring the Economic Dimensions of Urban Place Names. International Journal of Urban and Regional Research, 39-3, 435-450. http://dx.doi.org/c10.1111/1468-2427.12153 
Llobregat, E. A. (1969): Hacia una desmitificación de la historia antigua de Alicante. I. Nuevas perspectivas sobre viejos problemas. Revista del Instituto de Estudios Alicantinos, 1, 33-59.

Llobregat, E. A. (1970): Un supuesto epitafio de Hamílkar Barka. Revista del Instituto de Estudios Alicantinos, 4, 7-18.

Llobregat, E. A. (1972): Contestania Ibérica. Alicante: Instituto de Estudios Alicantinos.

Llorente, A. (1969): Toponimia e Historia. Discurso de apertura por el Catedrático de la Facultad de Filosofía y Letras Dr. D. Antonio Llorente Maldonado De Guevara, Universidad de Granada, 1969-1970.

Llorente, A. (1991): Los topónimos españoles y su significado. Documentos Didácticos, 104. Universidad de Salamanca: Instituto de Ciencias de la Educación, 1-58.

Luján, E. R. (1996): La onomástica celtibérica: actualización y aspectos comparativos. Veleia, 199-217.

Membrado-Tena, J. C. (2017): La relación entre toponimia urbana y topografía en la Ciutat Vella de Valencia. Análisis mediante métodos cuantitativos y cualitativos. Boletín de la Asociación de Geógrafos Españoles, 74, 361-386.

Membrado-Tena, J. C. e Iranzo-García, E. (2017): Los nombres de lugar como elementos evocadores del paisaje histórico. Análisis de la toponimia de los núcleos de población de la cuenca del Vinalopó. Investigaciones Geográficas, 68, 191-207. https://doi.org/10.14198/INGEO2017.68.11

Mira, B. (2006): El origen ibero-tartésico del euskera. Vision Net.

Mitchelson, M. L., Alderman, D. H. y Popke, E. J. (2007): Branded: the economic geographies of MLK streets. Social Science Quarterly, 88, 120-45. http://dx.doi.org/10.1111/j.1540-6237.2007.00450.x

Miranda, J. (1994): Toponimia e Historia. En: Álvarez, A. y Perdiguero, H. (eds.): Toponimia de Castilla y León. Actas de la reunión científica sobre toponimia de Castilla y León. Burgos, 1992, 217-222.

Morala, J. R. (1994): Objetivos y métodos en el estudio de la toponimia. En: Álvarez, A. y Perdiguero, H. (eds.): Toponimia de Castilla y León. Actas de la reunión científica sobre toponimia de Castilla y León. Burgos, 1992, 57-80.

Morel, J. P. (2006): Phocaean Colonisation. En Tsetskhladze, G. R. (ed.): Greek colonisation. An account of greek colonies and other settlements overseas. Leiden y Boston, Brill, 358428.

Moreu-Rey, E. (1982): Els nostres noms de lloc. Palma de Mallorca: Moll.

Moreu-Rey, E. (1995): Tipologia toponímica. En: Rosselló, V. y Casanova, E. (ed.): Materials de Toponímia, I. València: Generalitat Valenciana - Universitat de València, 45-52.

Nieto, E. (1997): Breve diccionario de topónimos españoles. Madrid: Alianza Editorial.

Olcina, M. (2005): La Illeta dels Banyets, el Tossal de Manises y la Serreta. En La Contestania ibérica, treinta años después. Actas de las I Jornadas de Arqueología Ibérica. Alicante, 147-178.

Olcina, M. (2009): Evolución histórica y urbana. Lucentum (Tossal de Manises, Alicante): arqueología e historia, 33-64.

Olcina, M., Guilabert, A. y Tendero, E. (2010): Lectura púnica del Tossal de Manises (Alicante). Mainake, 32, 1, 229-249. 
Pérez. M. I. y González, A. B. (2016): Summary of the evolution of the fortifications of Santa Barbara Castle in Alicante from its origins to the beginning of the eighteenth century. WIT Transactions on The Built Environment, 158. <http://dx.doi.org/10.2495/DSHF160021>

Poirier, J. (1965): Toponymie. Méthode d'enquête. Québec: Les Presses de l'Université Laval. Pokorny, J. (1959): Indogermanisches Etymologisches Wörterbuch. Berna: Francke

Riesco, P. (2010): Nombres en el paisaje: la toponimia, fuente de conocimiento y aprecio del $\begin{array}{lllll}\text { territorio. } & \text { Cuadernos } & \text { 7-34. }\end{array}$ $<$ http://revistaseug.ugr.es/index.php/cuadgeo/article/view/629/716>

Roca, C. y Rosser, P. (2003): La necrópolis tardorromana del casco antiguo de Alicante. A propósito de una reciente intervención antropológica. Bolskan, 20, 215-224.

Rose-Redwood, R. (2008): From number to name: symbolic capital, places of memory, and the politics of street renaming in New York City. Social and Cultural Geography, 9, 43152. http://dx.doi.org/10.1080/14649360802032702

Rose-Redwood, R., Alderman, D. H. y Azaryahu, M. (2010): Geographies of toponymic inscription: new directions in critical place-name studies. Progress in Human Geography, 34-4, 453-470. http://dx.doi.org/10.1111/j.14678306.1956.tb01510.x.10.1177/0309132509351042

Rosselló, V. (1998): Topònims del migjorn valencià a les cartes portolanes, 1280-1661 A sol post: estudis de llengua i literatura, 4, 101-110.

Rosser, P. y Fuentes, C. (2007): Tossal de les Basses: Seis mil años de historia de Alicante. Alicante: Patronato Municipal de Cultura.

Rosser, P. (2014): Arqueología del poblamiento de un territorio del mediterráneo occidental (Alicante, España) en época tardo-antigua. un espacio activo sin ciudad. Tesis doctoral.

Rubén, J. (2004): Diccionario toponímico y etnográfico de Hispania Antigua. Madrid: Minor Network.

Ruiz, E. (2002): Toponimia geográfica madrileña. Anales de Geografía de la Universidad Complutense, 431-441.

Sánchez, A. J. y Alonso, R. C. (2003-2004): El territorio alicantino en las fuentes geográficas árabes medievales (siglos IX-XV) miscelánea medieval murciana, XXVII-XXVIII, 103124.

Sauer, C. O. (1956): The education of a geographer. Annals of the Association of American Geographers, 46, 287-299. http://dx.doi.org/10.1111/j.1467-8306.1956.tb01510.x

Silgo, L. (2013): Estudio de toponimia ibérica: la toponimia de las fuentes clásicas, monedas e inscripciones. Valencia: Vision Libros.

Terrado, X. (2007): Cano / Germain / Kremer: Dictionnaire historique de l'anthroponymie romane. Estudis Romànics, 29, 381-386.

Tort-Donada, J. (2002): La toponímia com a camp de coneixement interdisciplinari. Algunes bases teòriques i epistemològiques per a l'estudi dels noms de lloc. Scripta Nova. Revista electrónica de geografía y ciencias sociales, $86<\mathrm{http}$ :/www.ub.edu/geocrit/sn-86.htm>.

Tort-Donada, J. (2003): Toponimia y marginalidad geográfica. Los nombres de lugar como reflejo de una interpretación del espacio. Scripta Nova. Revista electrónica de geografía y ciencias sociales, $138<\mathrm{http}$ :/www.ub.es/geocrit/sn/sn-138.htm>. 
Tort-Donada, J. (2008): Geography and touristic marketing. A study on the names of new settlements (housing developments) on the Mediterranean coast north of Barcelona (Maresme district, Catalonia, Spain). Onoma, Journal of the International Council of Onomastic Sciences, 43, 443-464.

Tort-Donada, J. (2010): Some Reflections on the Relation between Toponymy and Geography. Onoma, Journal of the International Council of Onomastic Sciences, 45, 253-276. http://dx.doi.org/10.2143/ONO.45.0.2182826

Tovar, A. (1955): Cantabria prerromana. Madrid, Universidad Internacional Menéndez Pelayo. Tros-de-Llarduya, M. (2005): Temporales marítimos y ordenación del territorio en la provincia de Alicante. Boletín de la Asociación de Geógrafos Españoles, 40, 329-350.

Untermann, J. (1998): La onomástica ibérica. Iberia, 1, 73-85.

Untermann, J. (2001): La toponimia antigua como fuente de las lenguas hispano-celtas. Palaeohispanica, 1, 187-218.

Urkola, M. (2010): Algunos datos de toponimia indoeuropea. Arse, 44, 17-66.

Villar, F. (1995): Los Indoeuropeos y los orígenes de Europa. Madrid: Gredos.

Villar, Francisco (1990): La línea inicial del bronce de Botorrita. Studia Indogermanica et Palaeohispanica in honorem A. Tovar et K. Mitxelena, Vitoria/Gasteiz, 375-392.

Villar, F. (2000): Indoeuropeos y no indoeuropeos en la Hispania prerromana. Las poblaciones y las lenguas prerromanas de Andalucía, Cataluña y Aragón según la información que nos proporciona la toponimia. Salamanca, Universidad de Salamanca, 2000.

Villar, F. y Fernández, M. P. (2001): Religión, lengua y cultura prerromanas de Hispania. Salamanca: Universidad de Salamanca.

Villar, F. (2014): Indoeuropeos, iberos, vascos y otros parientes. Salamanca: Universidad de Salamanca.

Whatmore, S. (2002): Hybrid geographies: natures, cultures, spaces. London: Sage. 